\title{
Los discursos de legitimación de los padres trabajadores chilenos sobre la reproducción del cuidado
}

\author{
Lorena Armijo Garrido \\ Universidad Santo Tomás, Santiago, Chile \\ Email: lorenaarmijoga@santotomas.cl
}

\begin{abstract}
Resumen:Actualmente existe un amplio debate académico acerca de la incorporación de los padres al cuidado de sus hijos asociado al surgimiento de patrones de comportamientos y de significados que modifican el orden de género, sin embargo, existe mínima evidencia empírica sobre las condiciones de su reproducción.Este artículo presenta los resultados de una investigación cualitativa basada en entrevistas y grupos de discusión con padres trabajadores chilenos de distintas clases sociales, desde la teoría de la reproducción social de Pierre Bourdieu.

En este grupo la legitimación del reparto desigual del cuidado en la familia radica en la arbitrariedad de la conjunción de condicionamientos sociales y simbólicos, tornándose imprecisa y naturalizada la identificación de responsabilidades, y en la resistencia a la apropiación deuna paternidadadaptada a los patrones de vida de las madres trabajadoras.

Palabras claves: Reproducción social, discursos de legitimación, cuidado, padres trabajadores.
\end{abstract}

\section{Working father's legimating discourses on care reproduction}

\begin{abstract}
Currently there is a wide academic debate about the incorporation of fathers into the care of their children associated with the emergence of new patterns of behavior and meanings that modify the gender order, however, there is little empirical evidence about the conditions of their reproduction. This article presents the results of qualitative research based on interviews and discussion groups with Chilean working fathers from different social classes, based on Pierre Bourdieu's theory of social reproduction. In this group, the legitimization of the unequal distribution of care in the family lies in the arbitrariness of the conjunction of social and subjective conditioning, making the identification of responsibilities imprecise and naturalized, and in the symbolic resistance to the appropriation of a fatherhood adapted to the life patterns of working mothers.
\end{abstract}

Keywords: Social reproduction, discourses of legitimation, care, working fathers.

\section{Os discursos legitimadores dos pais trabalhadores chilenos sobre a reprodução do cuidado}

Resumo: Hoje existe um amplo debate acadêmico sobre a incorporação dos pais trabalhadores ao cuidado de seus filhos, associado 
ao surgimento de novos padrões de comportamentos e significados que modificam a ordem de gênero, entretanto, há evidências empíricas mínimas sobre as condições de sua reprodução. Este artigo apresenta os resultados de uma pesquisa qualitativa baseada em entrevistas e grupos de discussão com pais trabalhadores de diferentes classes sociais, a partir da teoria da reprodução social de Pierre Bourdieu. Neste grupo, a legitimidade da distribuição desigual do cuidado na família está na arbitrariedade da conjunção de condicionamentos sociais e subjetivos, tornando imprecisa e naturalizada a identificação de responsabilidades, e na resistência simbólica à apropriação de uma paternidade adaptada aos padrões de vida das mães trabalhadoras.

Palavras-chave: Reprodução social, discursos de legitimação, cuidados, pais trabalhadores

\section{Introducción}

Hace más de una década José Olavarría (2001) profundizaba en Chile una línea de investigación sobre masculinidad y paternidad en medio de un debate internacional que venía a cuestionar las interpretaciones tradicionales del ser hombre.Desde ese tiempo, el autor plantea que los modelos de masculinidad y paternidad dominantes se han construido en base al trabajo remunerado y a la imagen del padre jefe de familia con hijos, a quienes otorga recursos, protege, ama y disfruta (Olavarría, 2001).

Una parte de los debates sobre la redefinición de la paternidad y las nuevas masculinidades se inserta en la sociología de la familia de origen francés,que identifica a la paternidad como un vínculo socializador no garantizado por la institución familiar, sino en construcción y apoyado por la subjetivación que la mujer hace al hombre para que participe en la esfera privada (Castelain-Meunier, 2002). En este contacto los hombres valoran su función paterna no sólo de manera autoritaria, sino también en la cotidianeidad(Segalen, 2013).Por su parte, el interés en los procesos de individualización y en el desacoplamiento de los comportamientos asociados a la vida familiar y matrimonial lo encontramos en los escritos ingleses, centrados enla desestabilización dela tradición y la reestructuración del trabajo doméstico y la fragilidad del sustento masculino (Beck, 2001; Beck y Beck-Gernsheim, 2003).Si bien el tradicional desequilibrio de poder entre padre e hijo se mantiene, con obligaciones vinculantes por ambas partes, se avanza en intimidad y sensibilización, sustituyéndose la autoridad paternal(Giddens, 1992).

Desde Chile se retoma el planteamiento francés de la metamorfosis de la familia, con hombres más preocupados por lo doméstico y mujeres más a su empleo que el hogar (Valdés, 2008) y la desestabilización de las bases sociales del pacto de género(Olavarría, 2013). Esto presiona a los hombres a ejercer diariamente su paternidad, influir en las decisiones fami- 
liares y en los procesos que ello implica, así como en las decisiones relativas a su fertilidad y fecundidad (Olavarría, 2008). El interés por la redefinición de la paternidad ha estado en medio de la crisis de la familia, la de la masculinidad, la del empleo y la del cuidado, capturando el interés sociológico; mientras ha queda relegado la comprensión de elementos sociosimbólicos legitimadores de la reprodución de género.Las expectativas de cambio social por parte de la comunidad sociológica obnubilan la evidencia empírica sobre la persistente y mayoritaria presencia de mujeres como cuidadoras (INE, 2009 y 2015).

Este artículo pretende aportar evidencia empírica de Chile al debate de la paternidad heterosexual y el cuidado de los hijos desde el marco teórico de la reproducción social de Pierre Bourdieu. Más que preguntar acerca de las condiciones de transformación sobre la cual se ha fundamentado la discusión actual, indago en el más elemental problema de la socialización (Cicourel, 1993)y sus bases inconscientes y contradictorias que permiten denunciar las estructuras latentes del orden de género.

Este documento está organizado en cuatro apartados: en el primero abordo la propuesta teórica de la reproducción social de Bourdieu, a partir de conceptos como habitus, campo y capitales y lo uno a una corriente de pensamiento relativa al cuidado; en el segundo presento los antecedentes metodológicos a partir de los cuales se produjo la información;en el tercerodescribo los resultados de la investigación en diálogo con otros estudios chilenos, en el cuartoreconstruyolos aspectos sociales y simbólicos que legitiman la reproducción de la paternidad dentro del orden de género. Finalmente, a modo de conclusión,reúno los principales hallazgos de la investigación.

\section{La reproducción del orden de género en la familia}

La definición del género como "elemento constitutivo de las relaciones sociales basadas en las diferencias que distinguen los sexos y como forma primaria de relaciones significantes de poder" por parte de Joan Scott (1996, p.291) ha permitido tomar distancia de la perspectiva feminista norteamericana que insistía, a mediados de los años ochenta, en las cualidades de la distinción sexual, en la primacía de la categoría“mujer” desligada de sus relaciones sociales y de cierto determinismo de los conceptos de género y diferencia sexual. Esta interpretación permite a Scott acercarse a la propuesta de reproducción social de Pierre Bourdieu para quién, según esta autora, la división del mundo basada en las diferencias biológicas y en la división del trabajo (re)productivo, esuna de las mejores ilusiones colectivas. En ambas versiones, el géneroes una categoría relacional y no sustancial relativa a las posiciones dentro de una estructura de relaciones de poder.

Los análisis empíricos de Bourdieu han aglutinado un cuerpo conceptual explicativo de lo social,en el cual la noción de habitus, campo y 
capitalpermiten abordar distintos niveles de las relaciones de poder y de las posiciones de los agentes en las estrategias de reproducción. Si nuestro interés son los discursos de legitimación de la reproducción del cuidado, su propuesta es adecuada pues permite el análisis del "interjuego de las categorías estructura y prácticas sociales, género y masculinidades (...) y favorece la construcción de un modelo teórico que pueda interpretar la agencia humana - en términos de género - y sus determinantes objetivas y subjetivas”(De Martino Bermúdez, 2013, p.285).

Desde los estudios de las masculinidades, una de sus más influyentes representantes, Raewyn Connell (1987) acude a Bourdieu para señalar que el género es una forma de expresión de las estructuras en el espacio de múltiple feminidades y masculinidades y, al mismo tiempo, un proceso de configuración de prácticas en el tiempo que delinea otros ámbitos de las relaciones sociales. La masculinidad en sus palabras sería la configuración de la práctica social ubicada simultáneamente entre varias estructuras de relación que siguen diversas trayectorias sociales, históricas y culturales (Connell, 1997). Sin embargo, Connell también se muestra crítica a las teorías de reproducción social -como la de Bourdieu- porque tenderían a inhibir más que aumentar la capacidad de acción de los agentes (Connell, 2013).

Connell se une así a una larga lista de críticos de Bourdieu que -entre algunas de las líneas de argumentación- ven en su corpus teórico: a) un reduccionismo en el impulso de la dominación y de su preservación mediante el uso de la violencia simbólica que deja sin efecto cualquier acción o cultura que no tenga poder de dominación; y b) un reproductivismo que no deja a los actores otro papel que no sea el portar y activar los campos de dominación, relegándolos a un lugar subordinado del estructuralismo sociológico (Alonso, 2002). La superación del dualismo objetivo-subjetivo que propone Bourdieu con el concepto de habitus (que pronto revisaremos) fracasa según Alexander (2001) y se revela como el "caballo de Troya” del determinismo de las estructuras sociales. Por el contrario, para el estadounidense, el agente posee una capacidad creativa y activa que le permite estar en una adaptación continua, mientras que los sistemas de valores (gran ausente en la propuesta bourdieusiana) tiene una independencia relativa frente a las estructuras, con la existencia de una cierta autonomía de la cultura.

Ambas críticas las considero infundadas porque el corpus de Bourdieu vuelve a poner -frente al estructuralismo del que proviene- el concepto de acción en el centro del debate sociológico. El francés rescata cierta noción de sujeto socialmente determinado que actúa estratégicamente en un espacio de poder, a partir del que reproduce sus distintos capitales (Alonso, 2002).

Con el concepto de habitus, concebido como una "disposición estratégica”, Bourdieu pretende romper el punto de vista objetivista y la idea de una estructura sin agente, al tiempo que otorga unaflexibilidad al con- 
cepto confiriéndole autonomía, alternativas y un espacio de juego (Giménez, 2002). Siguiendo a Durkheim, el habitus de Bourdieu es una especie de ley interior, producto de la internalización del ambiente, es un sistema de esquemas de pensamiento, de percepción, de apreciación y acción reproducidas y a la vez recreadas, generadoras de prácticas que representan la interiorización de la exterioridad y la incorporación de las condiciones objetivas de los campos a los sujetos (Bourdieu y Passeron, 1996; Bourdieu, 2007; Bourdieu, 2011). Por lo tanto, el habitus a) se adquiere; b) supone un dominio práctico que opera debajo de la conciencia y el discurso; c) sus disposiciones varían según la posición social y la trayectoria y; d) sus estructuras cognitivas son maleables y transmisibles gracias al trabajo pedagógico (Wacquant, 2010).

Entre las feministas no hay consenso acerca de la adhesión al concepto de habitus y, especificamente, sobre las posibilidades reales que tienen las mujeres de construir la experiencia personal a partir de sus preferencias. Algunas investigadoras como Hakim (2005) rechazan la primacía de las construcciones estructurales de quienes describen el sistema, en vez de indagar en las elecciones individuales. En ella aún resuena la crítica de Elster (en Kelso, 1994,p.37) cuando afirma que "los estructuralistas están más interesados en describir la cerca que lo que hacen las vacas detrás de ella”. En la vereda opuesta, Butler (2007, p.17) reconoce cierta vinculación del habitus con la dimensión ritual de la performatividad, entendida como "una repetición y un ritual que consigue su efecto a través de su naturalización en el contexto de un cuerpo”. Para esta autora el género es una copia sin origen, repitiendo una idea (anclada en campos de normas reguladas y no voluntarias) en cuya secuencia siempre hay fallas o desviaciones. Esta idea esta presente en Bourdieu cuando recuerda los versos del poeta R. Desnos: "del huevo del pelícano sale el enemigo del pelícano que atenta contra la vida del padre” (Bourdieu y Passeron, 1996, p.27); en clara alusión a la posibilidad de transformar el destino, de subvertir los modos y las normas de la reproducción social.

El habitus y el campo son dos modos de existencia de lo social, al habitus pertenece la acción individual, mientras que al campo las instituciones (Castón Boyer, 1996). El concepto de campo de Bourdieu designa el carácter específico de las determinaciones que ocurren en un espacio de interacciones donde se definen la posición que ocupan los distintos agentes. Cada campo es un sistema de relaciones objetivas de alianza o de conflicto, sin reducirse una a otra. Así el autor se acerca a la idea de Marx sobre las relaciones de fuerza entre dos clases en lucha. Un claro ejemplo de un campo, es la familia con sus relaciones de fuerza física, económica y simbólica y sus luchas por la conservación o conversión. Las fuerzas (afectivas) de fusión apuntan a debilitar y contrarrestar las fuerzas de la desintegración, pues como sujeto colectivo, la familia está destinada para y por la acumulación y transmisión de capitales. En cada campo existen relaciones de dominación y conflicto en las que los agentes tratan de hacer valer sus capitales económicos, culturales y sociales -los que están en permanente juego, aunque en estrecha relación y transformación continua bajo ciertas 
condiciones- para reproducir su poder o para modificar el campo en beneficio de su percepción de posición(Bourdieu, 1997).

La primera relación cercana de inculcación de las relaciones de fuerza se da en la familia, sin que los agentes puedan avanzar más allá de la descripción del mundo como evidente. En esta idea coincide las estructuras objetivas (condiciones sociales de posibilidad) y las estructuras subjetivas (significaciones internalizadas) incorporadas en la ilusión de una comprensión inmediata, sin posibilidad de cuestionamiento sobre la realidad o las condiciones sociales y sus significaciones (Bourdieu, 2007). En este campo, el habitus tiene propiedades que permiten asegurar su propia existencia y defensa ante el cambio social, y se logram mediante la generación de un conocimiento de sentido común, una doxa daba por sentada y que escapa del escrutinio crítico (Bourdieu, 2011).

Tanto la inculcación como la incorporación, es decir, sus condiciones de producción y reproducción suponen para la inculcación una acción pedagógica dentro de la familia y para la incorporación una interiorización de las regularidades inscritas en sus condiciones de existencia. La acción pedagógica está destinada a reproducir la arbitrariedad cultural de las clases dominantes, entendida como sistema de relaciones de fuerza y significados entre grupos o clases, por lo tanto, es objetivamente violencia simbólica (Bourdieu y Passeron, 1996). La noción de dominación en Bourdieu (2000) -recogida de Weber- remite a la existencia de la díada dominadores/ dominados en la cual los dominados aplican unas relaciones de dominación que provienen de los dominadores, naturalizándolas.

Los conceptos revisados de habitus, campo y capital permiten comprender la dominación masculina, especialmente, en lo que remite a su reproducción como dominación legítima. En este artículo, la paternidad está anclada en las estructuras inconscientes de la subjetividad del padre, lo que hace persistente su transformación y, al mismo tiempo, su incorporación en la estructura social orienta la acción de hombres y mujeres y otorga a las estructuras de dominación sexual cierta autonomía frente a las estructuras económicas (Arango, 2002). La articulación de estructuras sociales y psíquicas son aspectos latentes, pero eficaces de la dominación masculina, y la imposición, objetivación y legitimación de los códigos masculinos llegan a ser estructurantes del cuidado en la experiencia de la paternidad.

Una salida distinta a las posibilidades de transformar las estructuras de dominación la ofrece Nancy Fraser, quien relee a Bourdieu desde los discursos públicos de las necesidades. También se aleja deperformatividad y resignificación de Butler por considerar ambos conceptos en tanto propiedad abstracta y transhistórica del lenguaje, y no como parte del carácter realmente contradictorio de las relaciones sociales específicas. Su propuesta historizada permite -a su juicio- abordar de manera más adecuada la teoría social sin asumir las propuestas de desestabilización o desconstrucción (Fraser, 2006). En ella, el cuidado de los hijos por las familias se inscribe en 
la idea de régimen de cuidado, entendido como la provisión de cuidado según el tipo de recursos disponibles (Bettio y Plantenga, 2008). La salida sería un modelo denominado cuidador universal, que toma la vida de las mujeres como patrón e induce a los hombres de hacerse responsables del cuidado(Fraser, 1997)e incluye su institucionalización en la provisión de servicios de atención infantil (Ciccia \& Bleijenbergh, 2014). Con esto Fraser abre un debate sobre el fundamento normativo de los enfoques feministas del cuidado, la participación de ambos sexos en el empleo y el cuidado, y la independencia financiera de los cuidadores (Crompton 1999; Gornick \& Meyers 2008). El aporte de la autora es destacar en la necesidad de modificar los patrones de la masculinidad y de las relaciones laborales para alcanzar una participación más justa y paritaria ante el cuidado.

\section{Método y técnicas}

Los resultados que presentaré corresponden a un estudio cualitativo basado en una muestra estructural de29 entrevistas semiestructuradas y 8 grupos de discusión a padres trabajadores heterosexuales con pareja e hijos menores de edad a su cargo y residentes en el Gran Santiago.

En la aplicación de ambas técnicas de investigación, la población entrevistada compartió los siguientes atributos: edad ( 25 a 50 años) y tipo de contrato (definido e indefinido). Pero dichas técnicas se diferencian en el tipo de participación en el mercado laboral.

Las entrevistas semiestructuradas se organizaron, además, en función de la clase social definida“por la estructura de las relaciones entre todas las propiedades pertinentes, que confiere su propio valor a cada una de ellas y a los efectos que ejerce sobre las prácticas” (Bourdieu, 1998, p.104). La clase socialen este estudio fue operacionalizada a partir de la confluencia del conjunto de capitales individuales como recursos objetivos (económicos y sociales) y de los recursos políticos y culturales (Carabaña, 1993 enSalas, 2014).Esa diferenciación permitió la elaboración de los perfiles de entrevistados: (5) altos cargos con contrato definido y (5) con contrato indefinido, (5) administrativos y técnicos con contrato definidoy (5) con contrato indefinido, (5) trabajadores no cualificados definido con contrato definido y (4) con contrato indefinido.

Los grupos de discusión se organizaron en función de la distribución ocupacional. La evidencia muestra que el mercado laboral está segregado por sexo, con una concentración persistente de mujeres en un pequeño número de oficios y sectores,y una distribución de hombres en un abanico más amplio de ocupaciones (Maruani, 2004; Iglesias y Llorente, 2010). La segmentación horizontal fue operacionalizada a partir de los distintos sectores de actividad económica (INE, 2016): primaria, secundaria y terciaria. He considerado únicamente el sector secundario y el terciario en este estudio (4 grupos de discusión en cada uno). 
Los temas abordados recogen los significados de la paternidad y la experiencia del cuidado en medio de la conciliación trabajo y familia. Las categorías de análisis son: "significado de la paternidad”, "racionalización/ naturalización de la paternidad”, “dilema trabajo/familia”, y “conciencia de la desigualdad ante el cuidado”.

Este análisis tiene como premisa la producción de los discursos en una situación social y formulada desde determinados imperativos materiales y simbólicos que permiten la variación de las prácticas en función de cada situación. En otras palabras, en los discursos se establece una relación entre la producción de los “decires” (dimensión semántica) y los “haceres” (dimensión pragmática) (Martín Criado, 2014).Así “buscamos las líneas de enunciación simbólica que tienden a representar posiciones sociales, en los textos, como productos de actividad objetualizada”(Alonso, 2003:p. 203). Estos discursos pueden ser interdependientes, estratificados, competitivos y conflictivos entre sí, tensionándose lo que se debería hacer y lo que se hace, en tanto ejercicio de legitimidad frente a la que se posicionan (Martín Criado, 2010).

\section{a) Significados de la paternidad}

El ser padre es un punto de inflexión dentro del ciclo vital del grupo entrevistado, marcando una diferencia permanente en sus vidas entre las experiencias previas y las posteriores. Sus significados son variados y con escasa distinción entre las clases sociales debido a la presencia de un eje común: la responsabilidad de ser padre. Esta idea está presente en una serie de investigaciones anteriores donde los padres se asumen responsables de sus hijas/os en tanto proveedores, protectores, afectivos e interesados en el cuidado, aun cuando en nombre de esa responsabilidad justifiquen comportamientos contradictorios (Olavarría, 2001 y 2005; Valdés y Godoy, 2008; Valdés, 2009; Aguayo, et al., 2016; Madrid, 2017).

siento que es agarrar el capítulo de tu vida hasta antes que nacieran los niños y se cerró ese capítulo y para allá no vay a volver más(...) es el arte de postergarse (Pedro_alta_indefinido).

de las cosas que uno decide en la vida o gran parte de las cosas que yo decido en la vida por lo menos las decido pensando en ser padre (Rafael_alta_definido).

es una manera en el fondo, de ojalá no cometer los mismos errores que cometieron contigo (Carlos_media_indefinido).

la vida tiene muchos retos, entonces enseñarles muchas herramientas a ellos, enseñarles cómo enfrentarlos y como, perseverar pese a las dificultades que le va mostrando la vida uno puede salir adelante (Ciro_media_indefinido). 
con los hijos uno también aprendió a conocer cosas (Julio_baja_definido).

era un tiro al aire, cuando mi hijo nació era mi cable a tierra (...) con un hijo te cambia toda la vida totalmente, ahora me encuentroun papá responsable (Pablo_baja_indefinido).

Mi papá es un buen ejemplo, pero, una cosa in situ, o sea, una cosa en terreno es ser papá (hombres definidos servicios).

Estos hombres asumen la paternidad en construcción, como un aprendizaje permanente de ensayos y errores que marcan y forman parte de la cotidianeidad con los hijos y los años de crianza. Las equivocaciones son permitidas y se vuelven visibles tras la llegada de cada hijo, que trae una nueva oportunidad de enmendar errores, por ejemplo, destinar más tiempo y atención o ser afectuosos. Esta posibilidad de redimirse como acto de superación propia es convertida en virtud autoproclamada y diferenciación entre los padres, llegando a ser una instancia de disciplinamiento sin sanción pública, sólo subjetiva. Esta idea emerge entre los padres trabajadores de las capas medias y bajas que han tenido dos o más hijos y con espaciamiento de tiempo, mientras que en la clase alta no hay referencia de corregir actitudes o comportamientos.

La paternidad marca el tránsito de una vida centrada en sí mismo (con intereses particulares según las clases altas o como centrados en su propio bienestar en las clases bajas) a centrarse en otros como efecto de la permanencia de esta relación. Esta idea ya estaba presente en investigaciones anteriores donde ahora ellos deben responder por otros (Olavarría, 2001). La comunión con un otro (hijo o hija) se da en una relación recíproca, asimétricay condescendiente, asumida emocionalmente bajo la ética de la responsabilidad weberiana. El germen dela realización de conductas más igualitarias de cuidado estaría latente, pero como veremos más adelante, sin anclaje simbólico. A medida que descendemos en la escala social esta ética se impregna explícitamente de contenidos morales donde el deber se traspasa a los hijos acompañándolos de definiciones de un buen o mal hijo.

La paternidad suponeestos entrevistados una búsqueda de fusión con la comunidad a partir del reconocimiento de su individualidad como padre. Si antes eran sujetos indivisibles que velan por su propio bienestar,ahora se vuelven parte de la comunidad mediante la oportunidad de enseñar a otros y recrear sus propios valores y creencias de manera visible y continuada, haciendo de sus hijos un espejo de sus actos, un reforzamiento de sus creencias. Este inicio permitiría ser una nueva y mejorada versión de sí mismos, una copia que no deja de ser un otro ni tampoco el padre se lo apropia, sino que éste requiere la distancia para reflejarse en ella y constituirse en sujeto.

Los entrevistados perciben que pueden elegir significar su paternidad (y a medida que ascendemos en la escala social, agregan que eligen 
cómo vivirla) y tomar decisiones sobre los cuerpos de sus hijos. Esta elección se enfoca en la no repetición de historia vivida con sus propios padres, en los casos que hubo maltrato, abandono, negligencia, autoridad severa por sus padres y, soledad por ellos mismos, tal como vemos en otras investigaciones (Parrini, 2000; Olavarría, 2001). En estos padres, la elección de criar-cuidar, aunque sea por minutos al finalizar el día o a la distancia durante la jornada laboral, marca una distancia con sus propios padres, en versiones duales y no fragmentadas. El cuidado se construye en el discurso de manera racional, como una opción deseada desde la libre elección, no percibiéndolo como una fuente de obligatoriedad social (el deber ser padre), ni se perciben a sí mismos al servicio de la servidumbre biológica (sus cuerpos aptos para ser padre). Esta posibilidad de elegir es el fundamento de la constitución de la individualidad contemporánea y abre paso a la valoración de capacidades y titularidad de derechos, sin que esto necesariamente se convierta en una acción social.

El eje presencia/ausencia es un diferenciador del ser padre ya enunciado en investigaciones previas (Olavarría, 2001; Valdés y Godoy, 2008; Valdés, 2009). La presencia en el cuidado es legitimada con arugmentos biologicistas y psicoanalíticos.

Lo que pasa es que los apegos son distintos. También reconoce el apego del padre, por una cuestión biológica, porque el niño viene del vientre de la mujer (hombres definido servicios).

H1 y H2: el cordón umbilical se corta físicamente, pero la conexión siempre está, aunque uno como padre igual puede sentirlo (hombres definido industria).

pienso que esta experiencia de apego temprano del niño con la madre parece que es bien estructurante para la personalidad del niño (Efraín_alta_definido).

desde lo masculino uno se siente más completo en tanto tiene un clan, como hombre decir, tengo mi familia y tengo estos productos que son míos y es mi herencia genética en el mundo (...) es evolutivo, necesitamos reproducirnos los seres humanos porque los animalitos nos reproducimos, así que entonces así está la tarea cumplida (Anselmo_alta_indefinido).

yo creo que todo el mundo quiere dejar ahí sus genes plasmado en otro ser humano, que continúe la especie (...) de alguna manera sencilla de transcender es dejar un hijo (...) pero yo creo que eso es algo como de los animales, por instinto (Jesús_media_indefinido).

Yo pienso que es de la naturaleza, sobre todo bueno no todas las mamás amantan al hijo, se da todo como corresponde, por supuesto que se apega más a la mamá (Javier_baja_definido). 
En la mayoría de los discursos, el ser padre es diferente a ser madre, porque aun cuando ambos sexos pueden realizar las mismas tareas y algunos se muestran proclives a ello, emerge de manera sistemática un argumento basado en la naturaleza biológica como un destino trazado que marca decisivamente significados y prácticas. Los fundamentos del argumento biologicista son dos: el apego y la herencia genética. El primero puede basarse en un conocimiento racionalizado por la ciencia (que privilegia el apego de la madre) o biológico (que puede darse según algunos entrevistados en padres y madres), y el segundo, adquiere un carácter transcendental y aparece sólo en los hombres.

La primera fuente de legitimación de la naturaleza biológica puede observarse en la conformación de la tríada padre-madre-hijo en la que se establece un orden en las relaciones que condiciona lo deseado y esperado. En la díada madre-hijo, la centralidad del apego se funda de manera indivisible en el embarazo y lactancia, mientras que la díada padre-hijo el apego es al menos "distinto", y algunos abiertamente señalan que ellos ayudan a sus parejas en los procesos de maternalización como afirman las teorías clásicas del apego de Bowlby y Lamb. Sin embargo, no hay entre estos padres trabajadores una única interpretación, pudiendo encontrarse versiones que van desde la idea que ellos pueden tener un apego similar al de las madres hasta quienes lo remiten exclusivamente a las mujeres. En estos casos, la reivindicación de la díada madre-hijo alimenta la idea del "instinto maternal" como imagen de la maternidad que fija a las mujeres a su función reproductiva y se convierte en ideología dominante mediante una manipulación y reinterpretación social de la obligación femenina de convertirse forzadamente en madres cuando tienen hijos (Tubert, 2010; DiQuinzio, 1999 en Saletti Cuesta, 2008). En ambas versiones existiría una demanda de atención, protección y afecto del infante que es recogida y, eventualmente, satisfecha por la o el progenitor, al tiempo que otorga las bases emocionales para un adecuado desarrollo de la persona, no siendo posible escapar a lo dado por la naturaleza. Estos discursos esencializan la figura paterna o materna como mandatos simbólicos, sin dislocar la identificación padrehombre, madre-mujer, pues no hay pregunta acerca de una posible redistribución del cuidado en manos de otras personas que no sean los progenitores.

La segunda referencia a la naturaleza biológica remite a la imagen de la herencia filial como un deseo masculino inmanente, es un legado biológico de continuar existiendo más allá del limitado ciclo de vida. Este interés está presente en los hallazgos de una investigación previa que indica que la paternidad le permite al hombre sobrevivir simbólicamente como un pacto de herencia, en el cual los hombres entregan su nombre y su masculinidad heredando su hombría (Parrini, 2000). El legado se conecta con la trascendencia que permite la perdurabilidad de la conciencia humana (el ser, hacer, estar) y la negación del vacío existencial, de la irrelevancia social; lo desconocido convertido en incertidumbre, de la destrucción de la identidad y el destino. Cabe señalar que este discurso emerge entre los grupos medios, quienes portan los valores de la clase alta asociada al prestigio o reconoci- 
miento social, sin embargo, no son dueños de los medios de producción, por lo tanto, no pueden dejar (nuevos)productos culturales, sino sólo productos biológicos. Es una manera imaginaria de desplegar su visibilidad como agente social, de ser "alguien" dentro de ese grupo.

Si bien la herencia del padre biológico transmitida de manera consanguínea constituye la transferencia más inmediata de la especie, como un mandato primigenio inevitable,aparece con mayor saturación en estos discursos,el padre social con un reconocimiento más sustantivo y permanente (no fugaz como el momento de la concepción por el padre biológico). Este padre es el instaurador de la dimensión lingüísticay construye racionalmente el destino sobre el cual se posiciona el individuo, es la vivencia de la ley paterna en la cotidianeidad, es quien autoriza y mediatiza su incorporación al grupo. Es el padre real que se debate entre la presencia y ausencia, con hitos y situaciones en la historia del hijo, con emociones y cultura. Es cierto que la función paterna puede estar asociada a uno o varios hombres o personas, pero es el padre simbólico quien impone los límites sobre los cuales se actúa, los contornos de la ética y la masculinidad, el padre social requiere de la imagen del padre simbólico para poder existir social y subjetivamente. La transición discursiva del padre biológico al padre social se elabora en base a la rutinización y jerarquización de las normas convertidas en actos, y de éste al padre simbólico se fundamenta en el condicionamiento irreductible al ideal masculino, significante del reencuentro con la cultura patriarcal.

\section{b) El dilema de la conciliación trabajo/familia y la concientización de la desigualdad de género ante el cuidado}

Los padres trabajadores ante el cuidado deciden cuidar o no cuidar. Entre quienes reconocen la ausencia, su justificación radica en la adscripción a un modelo tradicional de familia o porque su empleo o estudios ocupan el tiempo que podrían destinar al cuidado. En uno u otro caso, este grupo sería el que se muestra menos permeable a la subversión del orden de género, mientras que los hombres que cuidan viven la conciliación trabajo/familia, impregnándose de ciertas prácticas, creencias e imágenes asociadas a ésta.

divide al hombre en dos, uno tiene que estar preocupado del entorno familiar, del sueldo, para poder ganar, para poder eh tener a tu hijo, vivir mejor y el otro es la parte sentimental que tiene el hombre (hombres definido industria).

no es tan sólo el trabajo, es más el estudio, porque de repente, a lo mejor mi hijo está despierto en las noches y tampoco puedo pasar ese tiempo con él porque tengo que estudiar (hombres definido industria).

esa queja de uno de mis hijos y pasó mucho tiempo, recién el domingo pasado nos dimos ese tiempo, fuimos al parque y jugamos a la 
pelota y quedó feliz y yo toda la semana cansado (hombres indefinido industria).

E1: Lo otro, es por un tema productivo de uno también, porque no sé po, imagínate estar trabajando con todas las presiones de la pega, y más encima, estar pendiente de la casa.

E2: Uno necesita esa tranquilidad, de poder saber que la otra parte está cubierta, y ahora tienes que darlo todo en tu trabajo, para poder llevar una casa (hombres indefinido servicios)

me voy al trabajo y estoy por WhatsApp. Entonces yo estoy, ¿cómo está?, ¿están bien?. Ya después al rato hago mis quehaceres y en tiempo de colación llamo, ¿cómo está el niño?, ¿cómo están?,¿les pasa algo?(hombres definido industria).

tengo la opción de estar presente (...) siempre he sido del tema de la calidad, porque yo puedo estar una hora con mi hija, pero a lo mejor, en esa media hora o esa hora, yo no estoy de pie, jugando o haciendo cariño, si no, que a veces estoy 15 minutos, pero son intensos (hombres indefinido servicios).

El conflicto entre vida familiar y vida laboral se ha traducido sociológicamente en un conflicto de roles, percibiéndose una escisión en el sentido de sus trayectorias vitales, entre el ser trabajador y el ser padre debido a la doble presencia en ambos mundos, una emocionalidad distinta para el empleo y otra para la familia, que genera estrés y/o cansancio y una pobreza de tiempo personal. Sin embargo, a diferencia de las madres trabajadoras que resuelven psicológicamente este conflicto en disonancia y culpa, estos hombres lo zanjan con aceptación y reconocimiento. Si bien se produciría una ampliación del ser padre incorporando el cuidado y los afecto, no existiría una subversión del orden de género propiamente tal, pues ellos siguen encarnando los valores masculinos y el cuidado viviéndolas desde su masculinidad, es decir, las tareas de cuidado pueden ser realizadas por cualquier persona, sin trastocar las definiciones de masculinidad (ni la feminidad). Esto se produce no sólo porque se dedican en menor medida al cuidado que las mujeres (aunque sea en ocasiones " 15 minutos, pero son intensos” hombres indefinido servicios), no exponiendo su subjetividad al sometimiento del deseo y poder de las mujeres, lo que le permite significar su trabajo como pleno y vivir un sentimiento y autoimagen de heroicidad, aunque sea incompleto y desigual (Lagarde, 2005). Sino también, porque en el compartir el trabajo de cuidado con las mujeres no se produce un acercamiento simbólico hacia ellas, no reconocen en las mujeres otra persona con quienes comparte historias comunes, no pueden reflejarse en ella pues no son sus iguales.

Es cierto que algunas investigaciones indican que los actuales padres chilenos se distancian de sus progenitores en el ejercicio de una paternidad activa en la crianza y viven las rupturas de la tradicional por la incorporación de aspectos subjetivos y emocionales (Valdés y Godoy, 2008; 
Valdés, 2009), y otras muestran una paternidad en transición que van desde introducir pequeños cambios en el cuidado hasta la restitución del poder patriarcal (Rebolledo, 2008). Sin embargo, mis resultados se acercan más bien al planteamiento que indica que los visibles cambios discursivos no han impactado de manera sustantiva en las prácticas ni en la imagen ni en el significado de la paternidad. Es frecuente que exista una tensión entre lo que debería hacer y lo que se hace realmente, desde los valores que los actores desean representar y las construcciones de situaciones que elaboran como ejercicio de legitimación frente a las que se posicionan(Martín Criado, 2010 y 2014). Los actores ajustan sus discursos según el orden de género imperante dándoles coherencia y aceptación social. Por lo tanto, me acerco más bien a las investigaciones que señalan que el interés por el cuidado de los hijos está más en el plano discursivo que en una corresponsabilidad práctica y cotidiana de padres y madres (Aguayo, Barker, \& Kimelman, 2016), encontrándose que ciertas actitudes relativas al cuidado coexisten con prácticas tradicionales del empleo, dando la imagen de un cambio real en el cuidado (Madrid, 2017).

Tanto la igualdad en el discurso como la imagen de un cambio real en el cuidado pueden explicarse desde la lógica de la reproducción social. La imagen de paternidad de quienes traspasan la porosa división sexual del trabajo no estaría en constante sospecha como ocurre en la imagen de la "buena madre”, aunque para su reconocimiento sí requiere actualizarse abiertamente como la madre. El "buen padre” requeriría ante todo un reconocimiento subjetivo e íntimo que enaltece su trabajo, lo que no minimiza que esperen que otros confirmen su valía. El cuidado se realiza desde su masculinidad en tanto complementariedad de la "buena madre”, nunca ocupando su lugar.La diferencia entre ambas imágenes radicaría no sólo en la condescendencia para con ellos respecto al deber del ser padre, son pocos a quienes se les pide socialmente la rendición de cuentas exigida a las madres, sino también en la confirmación de su masculinidad como experiencia que busca su idealización.

Estos padres trabajadores están convencidos subjetivamente que actúan bien (cuidan a sus hijos cuando pueden), pero a diferencia de las madres trabajadoras no viven la sobrecarga del trabajo. En la mayoría de los entrevistados no hay conciencia de la desigualdad ante el cuidado porque actúan paradójicamente con conciencia, sus actos son moralmente buenos, independiente de si son correctos o incorrectos, producto de la subjetivación de la moralidad, esta queda convertida en una cuestión manipulable, susceptible de cambiar. De ahí que la imagen del beso de las buenas noches propuesto por Madrid (2017) es una manifestación preclara de sus emociones efectivas en un instante fugaz, al finalizar el día, o durante los fines de semana o según la contingencia. Con sus actos definidos pueden resolver la tensión -que viven cotidianamente las madres trabajadoras- de transitar entre los distintos mundos del trabajo. 


\section{El cuidado de los hijos bajo el orden de género}

La paternidad es un producto cultural que los hombres vienen internalizando desde su infancia, alcanzando el punto de no retorno (como proyecto consumado) en el momento en que se vuelven padres sociales. La paternidad se reproduce en su cimiento más tradicional en la provisión de recursos materiales y se recrea en el cuidado y el afecto, confirmándose así la mejor versión de los valores socialmente aceptados de ser padres (cariñoso, inspira poder autoridad, proveedor, que cuida). Las prácticas del cuidado representan la internalización del habitus de la paternidad y las condiciones objetivas de la conciliación de las familias y los empleos (la distribución de la carga de trabajo, la asignación del espacio, las jornadas laborales, la extensión de permisos parentales).

El habitus tiene un carácter multidimensional: es a la vez eidos, ethos, hexis y aisthesis(Giménez, 2002). Estos padres trabajadores han inculcado un sistema de esquemas lógicos o estructuras cognitivas donde el ser padre apunta a la satisfacción de necesidades vitales (de subsistencia, mínimas o plenas). Su consecución requiere de disposiciones éticas del cuidado ("gran parte de las cosas que yo decido en la vida, las decido pensando en ser padre” Rafael_alta_definido), incluso en ausencia de ellas, sin restarle una asignación de coherencia práctica. El habitus de la paternidad se inscribe en los cuerpos de los hombres como un registro del comportamiento corporal: en el abrazo o la distancia que impone la separación, en miradas autoritarias o afectuosas según las circunstancias, incluso puede disfrutar de juegos, acercamientos e interacciones con sus retoños. Algunos mencionan el acto de mudar o alimentar,pero en la mayoríaqueda oculta la realización de labores “menos nobles"como la higiene básica o el lavado de ropa o trastos malolientes que, según Anderson (2001), en nuestra cultura puede constituir una ofensa a la dignidad humana.

Estos padres inculcan a hijos e hijas el ser padre con acciones cotidianas acerca del cuidadobajo las expectativas sociales del hacer familia según su clase social. De los padres de clase alta se espera además que sean exitosos en su empleo, mientras que en los de clase baja esta expectativa más que anularse por el apremio de la subsistencia, queda instalada como deuda de una masculinidad plena que no logran cumplir. Las clases dominantes no inculcarían las creencias de una repartición equitativa del cuidado entre la pareja porque la paternidad no requieretraspasar los límites impuestos de la masculinidad para ser reconocida.

En las relaciones de fuerza de la familia, el afecto de los padres hacia los hijos y la responsabilidad por su bienestar se convertirían en el motor que debilita su disolución y aminora los conflictos en la pareja. Las negociaciones relativas al cuidado dentro de la familia quedan supeditadas al control de los capitales individuales: el económico (el ingreso más importante), cultural (los valores y creencias relativas a la igualdad de género) y sociales (estrategias de conciliación) para imponerse en un juego permanente que reproduzca o modifique la actual posición. Estos padres trabaja- 
dores aprenden a jugar el juego del reparto del cuidado poniendo en tensión su posición en el campo familiar. El desplieguede capitales depende de la arbitrariedad de condicionamientos: individuales (el ánimo o motivación; el cansancio o el nivel de estrés), sociales (la horaria laboral), contextuales o geográficos (cercanías de colegios o jardines infantiles), y contingentes (enfermedades), volviendo imprecisa y naturalizada la identificación de responsabilidades. Por su parte, la pareja (madre trabajadora) reconoce la fluctuación de las tareas de cuidado,aceptándolas o rechazándolas según los recursos de conciliación que disponga personalmente.

La disposición estratégica del padre dentro de la familia también le permitiría cierta autonomía, con apertura de alternativas, que se legitima mediante la aprobación del principio de igualdad de género presente en los discursos públicos. Este tipo de discurso puede tener un poder performativo capaz de colaborar a su realización, y su eficacia dependerá en nuestro caso de dos aspectos: del reconocimiento otorgado al autor del discurso y de la relación con la objetividad del grupo, así como de las significaciones de estos discursos. Revisemos ambos argumentos.

Respecto al primero, cuando los padres trabajadores se muestran proclives a avanzar hacia la igualdad de género con una repartición más o menos equitativa del trabajo de cuidado podría aumentar la eficacia del discurso igualitarista. Sin embargo, la redistribución del cuidado supone socialmente permear a los varones del fenómeno de la "doble presencia" en el mundo del trabajo y la familia (tal como ocurre en las madres trabajadoras), lo que aumenta su disciplinamiento y, con ello, la expectativa de un mayor reconocimiento de este trabajo que no tiene.Aun cuando los varones diseñen estrategias para avanzar hacia prácticas igualitarias, viven la rutina de la reproducción del cuidado ordenada de principio a fin, en una secuencia de acciones encadenadas una tras otras como una "carrera de relevos", cuyo "testimonio" son los hijos que pasan de unos a otros durante el día en un ejercicio con reglas y estrategias sincronizadas (colegio, abuelas, nanas, tías, vecinas, padres). Así la experiencia vivida sustrae a los padres trabajadores una parte importante de las posibilidades de deshacer el orden de género.

Respecto al segundo, la eficacia del discurso de igualdad de género queda simbólicamente limitada por la conformación del mismo principio, pues ni su estructura ni los medios o procedimientos y menos sus resultados se constituyen como un proceso originario que pueda resolver la contradicción o lucha en la que se fundamenta. La ficción igualitarista ha propuesto el contra equilibrio de desigualdades como posibilidad para maximizar todas las dimensiones de la igualdad mediante el replanteo discursivo de nuevas necesidades y demandas, sin embargo, la resignificación del orden de género ha visto limitado sus pretensiones de validez pues en su tensión con las realizaciones fácticas de los padres trabajadores se ha centrada en respuestas consensuadas socialmente ante la escasez de recursos de conciliación (permisos parentales, sala cuna, subsidios para el cuidado), quedando pendiente la apropiación de los actos que supone una paternidad 
que persiga la dedicación de una gran cantidad de tiempo, energía y recursos y, al mismo tiempo, se adapte a los patrones de vida de las mujeres.

\section{Conclusiones}

El corpus teórico de Bourdieu es pertinente para abordar la pregunta acerca de los condicionamientos de las estructuras objetivas y simbólicas que legitiman la posición de los padres trabajadores ante el cuidado en la reproducción de la paternidad dentro del orden de género. Esta interrogante surgió en medio de los argumentos que afirman la actual presencia de un escenario más igualitario del cuidado como efecto de los cambios en la conformación de las familias europeas propuestos en la teoría de la individualización.

En este artículo parte de la premisa que tanto los sistemas simbólicos como las relaciones sociales pueden albergar contradicciones sin llegar a ser totalmente integrados, lo que no debilita su asociación ni las luchas y estrategias usadas para alcanzar su legitimación (Bourdieu, 1985; Martín Criado, 2014).

Entre los componentes sociales que encontramos en los discursos de reproducción de la paternidad de estos padres trabajadores está el fenómeno de la doble presencia, ya presente en las mujeres. Se trata deun despliegue de tareas de cuidado (y laborales) sincronizadas y rutinarias que debilitan un ejercicio de reflexibilidad por parte de los agentes sobre su propia experiencia de conciliación trabajo y familia. Estos agentes también requieren reconocimiento como padres, como las mujeres en tanto madres, sin embargo, esta búsqueda no es social como la de ellas (traducida en un malestar enquistado de manera subjetiva o social con potencial de convertir las necesidades de cuidado en demanda pública); sino más bien subjetiva recreándose en una versión benévola de masculinidad. Si bien este reconocimiento es favorable para la vivencia de la paternidad en sí (como acto heroico o deber), la subjetividad de sus actos de cuidado dentro de los patrones de género no contemplaría necesidades que pudiesen transfomarse en demandas. El camino del cuidado de los hijos por estos entrevistados tendría un menor potencial público, y la paternidad estaría más bien reafirmando una reprivatización del cuidado, distanciándose de ser asumido como un asunto de responsabilidad colectiva.

Entre los componentes simbólicos, el reconocimiento subjetivo de la labor del cuidado estos agentes lo realizan desde el ideal de masculinidad: con autoridad y afecto. En caso de vivir el dilema de la conciliación como sobre carga de trabajo, sus creencias y actitudes acerca de la masculinidad les impide masticar el malestar, tal como lo hacen las mujeres por socialización, así sus necesidades en torno al cuidado de los hijos se difuminan aún más. De esta manera, no se trastoca las definiciones de masculinidad ni feminidad. En las parejas en que hay una mayor corresponsabilidad del cuidado, en sintonía con los discursos públicos de igualdad de género, se 
reproduce el interés (como en las madres trabajadoras)por la escasez de recursos de conciliación (permisos parentales, sala cuna, subsidios), con una interpelación secundaria al orden de género, por lo tanto, se reproduce esta paternidad actual asociada al cuidado que se refuerza en la imagen del buen padre y en la condescendencia para con ellos respecto al deber del ser padre.

El reconocimiento subjetivo, la participación voluntaria y la redistribución contingente de tareas como fuentes de legitimación de la reproducción del cuidado en los discursos de estos padres trabajadores muestra los sutiles ajustes en las negociaciones dadas en el marco de la conciliación trabajo y familia, a las cuales los agentes recurren para explicar su experiencia vivida y otorgarle sentido en un ejercicio de historicidad que une racionalmente su pasado con las expectativas sociales actuales.

\section{Agradecimientos}

Este artículo forma parte de los resultados de la investigación CONICYT FONDECYT/Posdoctorado N³170459. 


\section{Bibliografía}

Aguayo, F., Barker, G., y Kimelman, E. (2016). Paternidad y cuidado en América Latina: Ausencias, presencias y transformaciones. Masculinities and Social Change, 5(2), 98-106.Recuperado de https:/ /www.researchgate.net/.../317589772_Estado_de_la_Paternidad _America_Latina_.

Alexander, J. (2001). La subjetivación de la fuerza objetiva: el habitus. Iztapalapa(50), 53-72. Recuperado de . revistaiztapalapa.izt.uam.mx/ index.php/izt/article/download/584/946

Alonso, L. E. (2002). Pierre Bourdieu in Memoriam (1930-2002). Entre la Bourdieumanía y la reconstrucción de la sociología europea. Reis. Revista Española de Investigaciones Sociológicas(97), 9-28. Recuperado de http://www.reis.cis.es/REIS/PDF/REIS_097_03.pdf.

Alonso, L. E. (2003). La mirada cualitativa en sociología. Una aproximación interpretativa. Madrid, España: Editorial Fundamentos.

Anderson, B. (2001). Reproductive Labour and Migration. Sixth Metropolis Conference. Rotterdam, Holanda: Oxford University, Economic and Social Research Council, Transational Communities Programme.Recuperado de http://www.transcomm.ox.ac.uk/.../ WPTC-02-01\%20Anderson.doc.pdf.

Arango, L. G. (2002). Sobre dominación y luchas: clase y género en el programa de Bourdieu. Revista Colombiana de Sociología, VII(1), 99118. Recuperado de https://core.ac.uk/download/pdf/18584620.pdf.

Beck, U. (2001). La sociedad del riesgo: hacia una nueva modernidad. Barcelona, España: Paidós.

Beck, U., y Beck-Gernsheim, E. (2003). La individualización. El individualismo institucionalizado y sus consecuencias sociales y políticas. Barcelona, España: Paidós.

Bettio, F., \& Plantenga, J. (2008). Care Regimes and the European Employment Rate. En L. Costabile (Ed.), Institutions for Social Well Being. Alternative for EuropeLondon: Palgrave Macmillan,152-175. Recuperado de https://link.springer.com/chapter/10.1057/ 9780230584358_7.

Bourdieu, P. (1973). Condición de clase y posición de clase. En Estructuralismo y Sociología. Buenos Aires, Argentina: Ediciones Nueva Visión.

Bourdieu, P. (1985). ¿Qué significa hablar?. Economía de los intercambios lingüísticos. Madrid, España: Akal. 
Bourdieu, P. (1998). La distinción. Criterio y bases sociales del gusto. Capítulo 2. Madrid, España: Taurus.

Bourdieu, P. (2000). La dominación masculina. Barcelona, España: Anagrama.

Bourdieu, P. (2007). El sentido práctico. Buenos Aires, Argentina: Siglo XXI Editores.

Bourdieu, P. (2011). Las estrategias de la reproducción social. Buenos Aires, Argentina: Siglo XXI Editores.

Bourdieu, P., y Passeron, J.-C. (1996). La reproducción. Barcelona; España: Distribuciones Fontamara.

Butler, J. (2007). El género en disputa. El feminismo y la subversión de la identidad.Barcelona, España: Paidós.

Castelain-Meunier, C. (2002). The Place of Fatherhood and the Parental Role. Tensions, Ambivalence and Contradictions. Current Sociology, 50(2), 185-201. Recuperado de https://is.muni.cz/el/1423/.../CastelainMeunier_fatherhood.pdf.

Castón Boyer, P. (1996). La sociología de Pierre Bourdieu. REIS(76), 7597.Recuperado de https://www.reis.cis.es/REIS/PDF/ REIS_076_06.pdf.

Ciccia, R., \& Bleijenbergh, I. (2014). After the Male Breadwinner Model?. Childcare Services and the Division of Labour in European countries. Social Politics, 21(1), 50-79. Recuperado de https://pure.qub.ac.uk/ ws/files/12745153/ciccia_socpol_libre.pdf.

Cicourel, A. (1993). Aspect of Structural and Processal Theories of Knowledge. En P. Bourdieu, C. Calhoun, E. LiPuma, y M. Postone, Bourdieu: Critical Perspective(pp. 89-115). Chicago: The University of Chicago Press.

Crompton, R., 1999. The gendered restructuring of the middle classes: employment and caring. The Sociological Review, 47(52), 165-183. https://www.researchgate.net/.../31255752_Gender_Restructuring.

Fraser, N. (1997). Iustitia Interrupta. Reflexiones críticas desde la posición “postsocialista”. Bogotá, Colombia: Siglo del Hombre Editores, Universidad de los Andes.

Giddens, A. (1992). La transformación de la intimidad. Madrid: Ediciones Cátedra.

Giménez, G. (2002). Introducción a la sociología de Pierre Bourdieu. Colección Pedagógica Universitaria, 37-38. 
Gornick, J. y Meyers, M. (2008). Creating Gender Egalitarian Societies. An Agenda for Reform. Politics \& Society, 36(3), 313-349. Recuperado de https://www.lisdatacenter.org/wp-content/.../gornick-meyers-ps2008.pd.

Hakim, C. (2005). Modelos de familia en las sociedades modernas. Ideales y realidades. Madrid, España: CIS.

Iglesias, C., y Llorente, R. (2010). Evolución reciente de la segregación laboral por género en España. Revista Universitaria de Ciencias del Trabajo $n^{\circ} 11,81-105$. Recuperado dewww3.uah.es/iaes/publicaciones/DT_13_08.pdf

INE. (2009). Encuesta experimental sobre uso del tiempo en el Gran Santiago. Antecedentes metodológicos y principales resultados. Santiago de Chile.

INE. (2015). ENUT Encuesta nacional sobre uso del tiempo. Santiago de Chile: Departamento de Estudios Sociales.

INE. (2016). Segmentación horizontal del mercado del trabajo. Caracterización de la ocupación por sexo. Santiago de Chile: Departamento de Estudios Laborales.

Kelso, W. (1994). Poverty and the Underclass: Changing Perceptions of the Poor in America. Three What Is Causing the Problem? An Overwiew. New York: New York University Press.

Lagarde, M. (2005). Los cautiverios de las mujeres. Madresposas, monjas, putas, presas y locas.México: Universidad Nacional Autónoma de México.

Madrid, S. (2017). The good night kiss: fatherhood among corporate managers and the reconfiguration of hegemonic masculinity in Chile. Internacional Journal of Masculinity Studies. Recuperado de https:// www.tandfonline.com/doi/full/.../18902138.2017.1362536.

Martín Criado, E. (2010). Las tallas grandes perjudican seriamente la salud. La frágil legitimidad de las prácticas de adelgazamiento entre las madres de clases populares. RIS, Vol.68, n² , mayo-agosto, 349-373.Recuperado de https://revintsociologia.revistas.csic.es > Inicio > Vol 68, No 2 (2010) > Martín-Criado.

Martín Criado, E. (2014). Mentiras, inconsistencias y ambivalencias. Teoría de la acción y análisis de discurso. RIS, V.72, $n^{\circ} 1$, enero-abril, 115-138.Recuperado de https://revintsociologia.revistas.csic.es > Inicio > Vol 72, No 1 (2014) > Martín Criado. 
Maruani, M. (2004). Hombres y mujeres en el mercado del trabajo: paridad sin igualdad. Revista de Economía Mundial, 10(11), 59-75.Recuperado de https://www.sem-wes.org/sites/default/files/revistas/rem1011_3.pdf.

Olavarría, J. (2001). Y todos querían ser (buenos) padres. Santiago de Chile: FLACSO.

Olavarría, J. (2008). Distribución del trabajo en las familias y (nuevas) masculinidades. Cepal Serie Seminarios y conferencias 52, 77-84.Recuperado de https://dds.cepal.org/eventos/presentaciones/2007/1122/ Resumen.JoseOlavarria.pdf.

Olavarría, J. (2013). La crisis del contrato de género y las masculinidades. En C. Mora, Desigualdad en Chile: la continua relevancia del género (pp. 301-323). Santiago de Chile: Ediciones Universidad Alberto Hurtado.

Parrini, R. (2000). Los poderes del padre: paternidad y subjetividad masculina. En J. Olavarría, y R. Parrini (Edits.), Masculinidad/es. Identidad, sexualidad y familia (pp. 69-77). Santiago de Chile: Red Masculinidad Chile, Universidad Academia Humanismo Cristiano y FLACSO Chile.

Rebolledo, L. (2008). Del padre ausente al padre próximo. Emergencia de nuevas formas de paternidad en el Chile actual. En K. Araujo , y M. Prieto (Edits.), Estudios sobre sexualidades en América Latina (pp. 123-140). Quito: Flacso Ecuador.

Salas, C. (2014). La relación de las mujeres con el empleo: actitudes, conflictos y estrategias. Madrid, España: Cuadernos de Investigación, Universidad Complutense.

Saletti Cuesta, L. (2008). Propuestas teóricas feministas en relación al concepto de maternidad. Clepsydra, 169-183.Recuperado de https:// d ig ibug.ugr.e s/bits tream/10481/14 802 / . . / Saletti_Cuesta_articulo_revista_clepsydra.pdf.

Scott, J. (1996). El género: una categoría útil para el análisis histórico. En M. Lamas, El género: la construcción cultural de la diferencia sexual. México DF, México: PUEG.

Segalen, M. (2013). Sociología de la familia. Mar del Plata, Argentina: EUDEM.

Tubert, S. (2010). Los ideales culturales de la feminidad y sus efectos sobre el cuerpo de las mujeres. Quaderns de Psicología, V.12, $n^{\circ} 2$, 161174.Recuperado de https://www.quadernsdepsicologia.cat > Inicio > Vol. 12, Núm. 2 (2010) > Tubert. 
Valdés, X. (2008). Notas sobre la metamorfosis de la familia en Chile. En I. Arriagada, Futuro de las familias y desafíos para las políticas (pp. 41-58). Santiago de Chile: CEPAL.

Valdés, X., y Godoy, C. G. (2008). El lugar del padre: rupturas y herencias. Representaciones de la paternidad en grupos algo, medios y populares chileno. Estudios Avanzados, 6(9), 79-112.Recuperado de https:/ /menengage.org/wp-content/uploads/2014/06/lugar-del-padre.pdf.

Wacquant, L. (2010). L’habitus comme objet et méthode d’investigation. Retour sur la fabrique du boxeur. Actes de la recherche en sciences sociales 2010/4 (n 184),p. 108-121. Recuperado de https://https:// www.cairn.info/revue-actes-de-la-recherche-en-sciences-so.

Recibido: 07.05.18

Aceptado: 31.07 .18 